\title{
Correction to: An Experimental Study on Pressurization Smoke Control System in Staircase
}

Hyun woo Park, Tomohiro Mitsumura, Yoshifumi Ohmiya, Masashi Kishiue, and Wataru Takahashi

\section{Correction to:}

\section{Chapter "An Experimental Study on Pressurization Smoke Control System in Staircase" in: G.-Y. Wu et al. (eds.), The Proceedings of 11th Asia-Oceania Symposium on Fire Science and Technology, https://doi.org/10.1007/978-981-32-9139-3_12}

The original version of the book was published with subtitle for this Chapter "An Experimental Study on Pressurization Smoke Control System in Staircase" now subtitle has been updated from "Influence of a Dynamic Pressure Control System Opening Vestibule Doors Confirmation of Differential Pressure Adjustment Damper Performance" to "Influence of a Dynamic Pressure Control System and Opening Vestibule Doors and Confirmation of Differential Pressure Adjustment Damper Performance".. The chapter and book have been updated with the change. 